\title{
Surgical Infections in Low- and Middle-Income Countries: A Global Assessment of the Burden and Management Needs
}

\author{
Jennifer Rickard, ${ }^{1}$ Gregory Beilman, Joseph Forrester, ${ }^{1}$ Robert Sawyer, ${ }^{3}$ \\ Andrew Stephen, ${ }^{4}$ Thomas G. Weiser, ${ }^{2}$ and Julie Valenzuela ${ }^{5}$
}

\begin{abstract}
Background: The burden of surgical infections in low- and middle-income countries (LMICs) remains poorly defined compared with high-income countries. Although there are common infections necessitating surgery prevalent across the world, such as appendicitis and peptic ulcer disease, other conditions are more localized geographically. To date, comprehensive assessment of the burden of surgically treatable infections or sequelae of surgical infections in LMICs is lacking.

Methods: We reviewed the literature to define the burden of surgical infections in LMICs and characterize the needs and challenges of addressing this issue.

Results: Surgical infections comprise a broad range of diseases including intra-abdominal, skin and soft tissue, and healthcare-associated infections and other infectious processes. Treatment of surgical infections requires a functional surgical ecosystem, microbiology services, and appropriate and effective antimicrobial therapy. Systems must be developed and maintained to evaluate screening, prevention, and treatment strategies. Solutions and interventions are proposed focusing on reducing the burden of disease, improving surveillance, strengthening antibiotic stewardship, and enhancing the management of surgical infections.

Conclusions: Surgical infections constitute a large burden of disease globally. Challenges to management in LMICs include a shortage of trained personnel and material resources. The increasing rate of antimicrobial drug resistance, likely related to antibiotic misuse, adds to the challenges. Development of surveillance, infection prevention, and antimicrobial stewardship programs are initial steps forward. Education is critical and should begin early in training, be an active process, and be sustained through regular programs.
\end{abstract}

Keywords: antimicrobial resistance; antimicrobial stewardship; infection control; infections; surgery

$\mathbf{T}$ HE BURDEN OF SURGICAL INFECTIONS in low- and middle-income countries (LMICs) remains poorly defined compared with high-income countries (HICs) [1]. Whereas there are common infections necessitating operations prevalent across the LMIC world such as appendicitis and peptic ulcer disease associated with Helicobacter pylori, other conditions such as leishmaniasis or filariasis are more localized geographically. Surgical infections require a combination of effective operative management as well as proper antimicrobial therapy. The purpose of this review is to summarize current understanding of global infectious diseases treated by operations, as well as the infectious sequelae of invasive procedures (Fig. 1).

\section{Burden of Surgical Infectious Disease in Low- and Middle-income Countries}

To our knowledge, there has been no comprehensive assessment of the number of operatively treatable infections or sequelae of surgical infections in LMICs. Existing global

\footnotetext{
${ }^{1}$ Department of Surgery, University of Minnesota, Minneapolis, Minnesota, USA.

${ }^{2}$ Department of Surgery, Stanford University, Stanford, California, USA.

${ }^{3}$ Department of Surgery, Homer Stryker MD School of Medicine, Western Michigan University, Kalamazoo, Michigan, USA.

${ }_{5}^{4}$ Department of Surgery, Warren Alpert Medical School, Brown University, Providence, Rhode Island, USA.

${ }^{5}$ Department of Surgery, Northwell Health, New Hyde Park, New York, USA.
} 


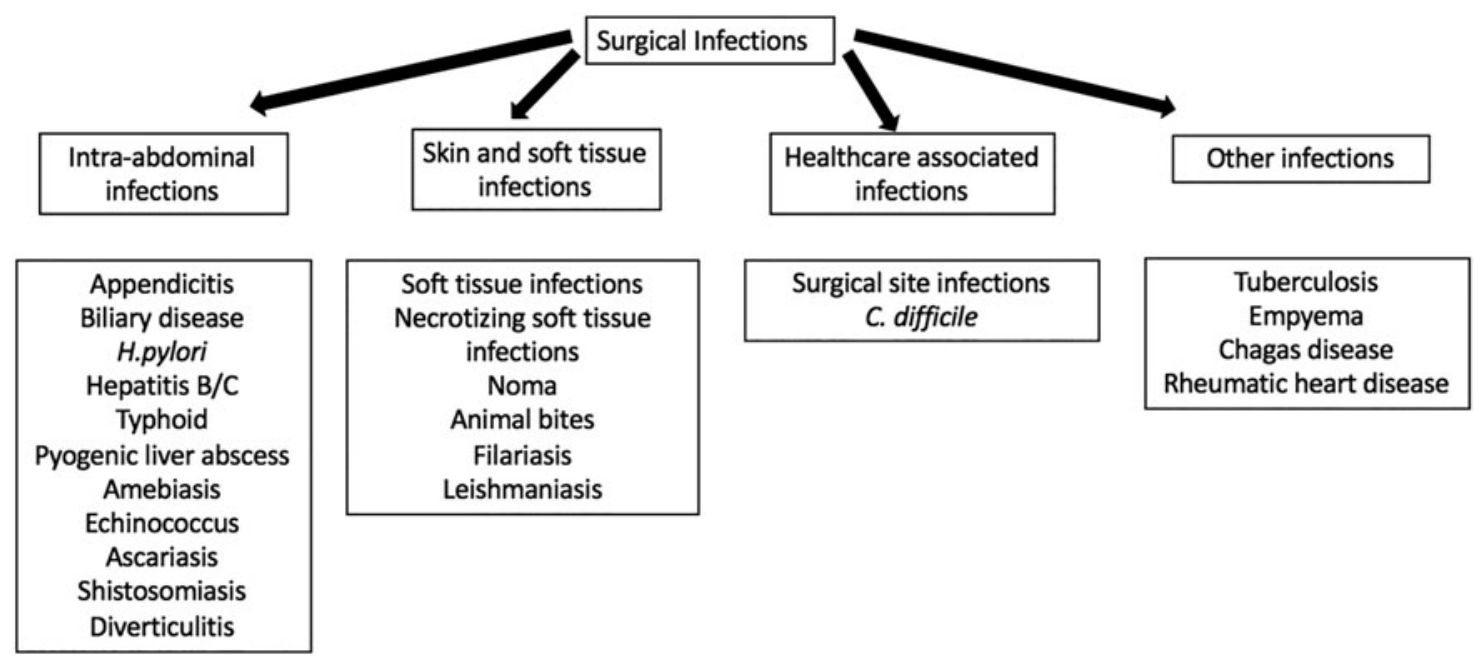

FIG. 1. Surgical infections in low- and middle-income countries.

estimates of surgical needs such as the World Health Organization (WHO) Global Burden of Disease Program (GBD) do not categorize many infectious pathologies necessitating operative intervention independently, despite infections clearly being "any pathology for which an invasive procedure may provide treatment, palliation, or cure" [2]. To the extent possible, we provide a summary of current estimates of sur-

TABle 1. Surgical INFECTIONS AND OPERATIVE INTERVENTIONS

\section{Infectious Pathologies Requiring Operation}

Cardiac

Pulmonary

GI

Rheumatic Heart Disease

Tuberculosis

Empyema

Appendicitis

Biliary disease

H. Pylori, PUD

Diverticulitis

Hepatitis C

Hepatocellular Carcinoma

Typhoid Intestinal perforation

Pyogenic Liver Abscess

Amebiasis

Echinococcus

Ascariasis

Liver Flukes

Oesophagostomiasis

CMV perforation

Chagas

Skin, Soft Tissue, Bone Osteomyelitis

Necrotizing fasciitis

Vascular disease

Diabetic complications

Traumatic Injuries

Bites

Stings

Venom

Lymphatic filariasis

Leishmaniasis

Noma

Infections Due to Operative Interventions

Healthcare Associated

Infections

SSI

C Difficile gical infectious disease in LMICs, defining surgical infections as any infectious process requiring operative intervention or any infection caused by an operative process (Table 1).

\section{Intra-Abdominal Infections}

\section{Appendicitis}

In 2017, the global incidence of appendicitis was 19 million [3]. In 2010, appendicitis resulted in an equivalent number of deaths in LMICs and HICs but was associated with considerably more years of life lost and disability-adjusted life-years [4-6]. Studies from LMICs have shown population frequencies of appendicitis that are lower than, or comparable to, that in HICs [7-10]. In LMICs, appendicitis tends to present later in the natural history of the disease, frequently with gross perforation [6,11-13] that may contribute to the elevated surgical site infection (SSI) rates $(17.9 \%)$ seen with appendectomy in LMICs [13]. Although the utility of nonoperative management of uncomplicated appendicitis has been documented, most cases of appendicitis, especially complicated disease, are managed with appendectomy [14].

\section{Biliary disease}

In 2017, the global prevalence of nononcologic biliary disease was 30.6 million [3]. Each year, 3\%-4\% of U.S. patients with gallstones undergo operation, making it the most common elective abdominal procedure [15]. Reported morbidity and mortality rates associated with biliary disease are considerably lower in LMIC settings. As the Western diet and lifestyle become more common in LMICs, however, it is possible this trend will reverse; and cholesterol gallstone disease resulting in cholecystitis will become more common [16,17].

\section{Helicobacter pylori and peptic ulcer disease}

In 2017, the prevalence of peptic ulcer disease (PUD) was 17.2 million [3]. In 2015, 60\% of the world's population (an estimated 4.4 billion individuals) were infected with $H$. pylori [18]. Considerable regional variation has been noted, with a greater prevalence of disease in Africa, South America and the Caribbean, and Asia [18,19]. Untreated, long-term 
infection with $H$. pylori may lead to PUD in $10 \%$ of patients with 1\%-3\% developing gastric adenocarcinoma [20,21]. Indications for operative intervention in PUD include bleeding, perforation, obstruction, and intractable disease. Peptic ulcer disease is the leading cause of disability and death among all indications for emergency general surgery in LMICs, with $85 \%$ of PUD-related deaths occurring in such countries [4,5,22].

\section{Hepatitis $B$ and $C$ and hepatocellular carcinoma}

Hepatitis B virus (HBV) has been estimated to infect between 240 million and 350 million persons worldwide, with much of the burden of disease falling on LMICs, the Asia Pacific and sub-Saharan Africa regions in particular [23-27]. Of the 786,000 HBV-associated deaths in 2010, 341,000 (43\%) were attributed to hepatocellular carcinoma (HCC). Similarly, hepatitis $\mathrm{C}$ virus (HCV) was estimated to infect 185 million persons worldwide in 2005, with the highest prevalence ( $>3.5 \%$ infected) in Central and East Asia and North Africa and the Middle East [28]. Infection with HCV increases the risk of HCC 15-20-fold by inducing fibrosis and cirrhosis [29]. Two thirds to $80 \%$ of HCC occurred in the Western Pacific or sub-Saharan Africa, where liver carcinoma is the fourth most common type of cancer $[4,25,30]$. It is not known how many of these patients with HCC underwent, or could have undergone, operation [31-33]. In Africa, the incidence of HCC correlates closely with the fatality rate, suggesting late diagnosis, few available therapeutic options, or both [30,33].

\section{Typhoid intestinal perforation}

In 2000, an estimated 21 million cases of typhoid fever and 216,000 deaths occurred worldwide [34]; this increased to 26.9 million cases annually as of 2010 [35]. More than half of the cases of typhoid fever are estimated to occur in LMICs, although the figure may underestimate grossly the number of infections in endemic settings [36]. Salmonella typhii, the causative agent of typhoid fever, can be found in the Peyer's patches in the small bowel and can sequester in the gallbladder. Among seven national-level studies reporting secondary outcomes of typhoid fever, intestinal perforation rates ranged from 0-4\% [36]. Management of typhoid intestinal perforation is operation for bowel repair and source control. The overall case fatality rate is $15 \%$ [37].

\section{Pyogenic liver abscess}

The frequency of pyogenic liver abscess differs considerably by region [38]. Historically, the most common cause of a pyogenic liver abscess has been appendicitis, although this has changed over time to cholecystitis $[39,40]$. There are no recent national- or regional-level epidemiologic studies of pyogenic liver abscess in developing countries. In the U.S., it is responsible for 2.3 hospital admissions per 100,000, increasing to 275 per 100,000 admissions per 100,000 in Taiwan [38].

Management of pyogenic liver abscess centers on treating the underlying cause, drainage of abscesses, and systemic antibiotic therapy. Drainage can be accomplished through percutaneous, interventional, laparoscopic, or open means [41]. Small abscesses $(<3-5 \mathrm{~cm})$ usually resolve with appropriate antibiotics without operative intervention; larger abscesses $(>5 \mathrm{~cm})$ may be served best by operative drainage.

\section{Amebiasis}

In 1986, an estimated $10 \%$ of the world's population was estimated to be infected by Entamoeba histolytica, with only $1 \%$ of infected individuals experiencing invasive disease [42]. These values now are believed to be overestimates as a consequence of separation of the pathogenic species $E$. histolytica from the non-pathogenic Entamoeba dispar [43]. Operation may be required for complications of primary infection such as perforation, stricture, or bleeding of the intestine. Between 3\%$6 \%$ of patients progress to fulminant amebic colitis necessitating operative intervention with a mortality rate ranging from $57 \%-100 \%$ [44-46]. Amebic liver abscess, occurring in $\sim 1 \%$ of infections, also may require operative intervention $[47,48]$.

\section{Echinococcus}

In 2007, 4 million persons worldwide were estimated to be infected with Echinococcus granulosus or Echinococcus multilocularis, the causative organisms of cystic echinococcosis and alveolar echinococcosis, respectively [49]. In 2010, 1,200 deaths were attributed to echinococcosis $[4,5,49]$. Operative resection of cysts and cystic lesions is a mainstay of treatment. Although anti-helminthic chemotherapeutic regimens may result in cure rates of $30 \%$ or more, nearly $70 \%$ of infected patients will benefit from operative intervention [49].

\section{Ascariasis}

Ascariasis is a common helminthic infection worldwide, with nearly $25 \%$ of the world's population infected [50]. No existing population-based studies examine the frequency of operative disease among infected persons. However, operative pathology attributable to ascariasis is well-described and includes appendicitis, Meckel's diverticulitis, volvulus, intestinal obstruction, intussusception, perforation, and biliary and pancreatic obstruction [7,51-54].

\section{Schistosomiasis}

More than 200 million people worldwide are infected with Schistosoma [55]. Acute operative conditions such as appendicitis, Meckel's diverticulitis, and cholecystitis in endemic regions are rarely described [7,56-59]. More common chronic conditions amenable to operation are bladder cancer [60] and portal hypertension [61-63].

\section{Liver flukes}

Infection with Clonorchis sinensis results after ingestion of raw fish contaminated with infective cysts. An estimated 15-20 million people globally are infected [64]. Rarely, infection can necessitate operative intervention for acute processes such as obstructive jaundice, cholangitis, or cholecystitis [65-71]. Other indications for operative intervention are sequelae of chronic infection such as mucinous cystadenoma [72] or cholangiocarcinoma [64]. Similarly, Fasciola spp. liver flukes are estimated to infect 2 million individuals worldwide and cause biliary ductal dilation and other biliary pathology [73-78].

\section{Oesophagostomiasis}

Oesohagostomiasis is caused by worms of the family Strongylidae (Oesophagostomum bifurcum, O. apiostomum, 
and $O$. stephanostomum among others), which is characterized by acute abdominal pain mimicking appendicitis, intestinal obstruction, painless cutaneous masses in the lower abdomen, and, rarely, bowel perforation [79]. These worms are endemic or potentially endemic in 36 countries predominately in Africa, South America, and southeast Asia and infest approximately 250,000 persons whereas more than $1,000,000$ persons are at risk of infestation [80-83]. The antihelminthic drug albendazole is the mainstay of treatment [84]. Surgeons may be involved in cases of misdiagnosis or if there are complications of nodular disease such as bowel obstruction, peritonitis, or intestinal volvulus.

\section{Cytomegalovirus perforation}

Cytomegalovirus (CMV), a member of the Herpesviridae family, usually is acquired in childhood [85]. The estimated global seroprevalence is $83 \%$, although this may be even higher in lower-resource settings such as Africa and Southeast Asia [86,87]. Infants, recipients of solid organ transplants, and other immunosuppressed patients, particularly those with human immunodeficiency virus (HIV) who have a $\mathrm{CD}_{4}$ count $<50$ per $\mathrm{mm}^{3}$ are at greatest risk of clinical sequelae of infection [85,88]. Gastrointestinal manifestations have been found to affect $<1 \%-14 \%$ of HIV-infected patients in Africa, although rigorous epidemiologic studies of CMV infection among persons living in LMICs are limited [87-89]. Complications likely to be encountered by surgeons are colitis, gastritis, esophagitis, duodenitis, pancreatitis, peritonitis, intestinal perforation, and splenomegaly. Epidemiologic assessments of the surgical burden of CMV infection in LMIC settings are lacking.

\section{Diverticulitis}

Historical accounts from surgeons in LMICs rarely identify diverticulitis as an indication for operation [90]. Few population-based estimates of diverticular disease exist for diverticulitis in LMICs, and those that do are single country or single institution [22,91-93]. As diets and lifestyle patterns change, an increase in diverticulitis in LMICs may be anticipated [91-93].

\section{Skin, Soft Tissue, and Bone Infections}

Extremity soft tissue wounds may be attributable to a wide range of etiologies, including vascular disease, diabetes, and trauma. Any trauma or wound, particularly those poorly managed, may progress to skin and soft tissue infection. There are no estimates of the number of skin and soft tissue infections in LMICs. Soft tissue infections are associated with 1.5 times the number of deaths in LMICs as in HICs, with concomitantly greater years of life lost and disability-adjusted life-years [22].

\section{Trauma}

The burden of infection after traumatic injury is considerable in LMIC settings. There are more than 4 million fatalities annually from traumatic injury, with $88 \%$ of injury-related deaths occurring in LMICs $[4,94,95]$. The true incidence of skin or soft tissue infection after traumatic injury in LMIC countries has not been defined. However, evaluation of infection after orthopedic fixation of traumatic fractures is not particularly encouraging. Skin and soft tissue infections after operative fixation of open fractures is common in LMIC settings, with rates up to three times those found in HIC settings [96].

\section{Osteomyelitis}

Although osteomyelitis may occur after injuries or other soft tissue infections and represents a large healthcare burden in LMICs, to our knowledge, there are no population-level data. In Ugandan hospitals, osteomyelitis accounted for $10 \%$ of all operative procedures [97]; little data exist beyond individual facility reports, and GBD does not provide any assessment of this condition. A review of infections after open reduction and internal fixation of long bones for trauma in LMICs identified an infection rate of 6.4 per 100 procedures; open fractures had an infection rate of 18 (95\% confidence interval [CI] 13.9-23.0) infections per 100 procedures [96]. A high incidence of road traffic collisions coupled with personnel, facility, and other resource challenges limit the ability to render timely and definitive fracture management, contributing to this burden. In fracture management, early washout of open fractures and internal or external fixation allows earlier return to ambulation, function, work, and independence. If antibiotic administration, washout, and fixation of open fractures are not performed in a timely fashion, the risk of non-union and acute and chronic osteomyelitis is significant.

\section{Diabetes mellitus and peripheral vascular disease}

There are 496 million people globally with diabetes mellitus and 118 million people globally with peripheral arterial disease (PAD) [3]. The prevalence of PAD in sub-Saharan Africa may be equal to or higher than that in HICs, exceeding $50 \%$ in some high-risk populations [98]. The prevalence of PAD ranges from $3 \%-24 \%$ in adults age older than 50 years. The prevalence is even higher $(39 \%-52 \%)$ in persons with known risk factors such as diabetes mellitus [98]. The number of persons affected worldwide is expected to double by 2030, with an anticipated 485 million people affected. This increase will affect LMICs disproportionately, with nearly two thirds of all new cases originating in these countries [99]. Common complications of diabetes mellitus are peripheral neuropathy and peripheral vascular disease, which can lead to diabetic foot infections. These infections require operative debridement and potentially amputation. The number of associated skin and soft tissue infections anticipated with a global increase in chronic diseases including peripheral vascular disease and diabetes has not been quantified but likely will be substantial.

\section{Necrotizing soft tissue infections}

Necrotizing soft tissue infections, including necrotizing fasciitis and Fournier's gangrene, may occur as a result of untreated soft tissue infections or de novo. There are few existing country- or regional-level studies assessing the burden of necrotizing soft tissue infections in LMICs, with most studies retrospective, descriptive, hospital-level assessments or compilations of case reports [100,101].

\section{Bites/Stings/Venom}

Animal bites are a common problem in LMICs and may require operative management or surgical consultation. There 
is no global estimate of the total annual number of animalhuman bite injuries, although the burden may be considerable in rural and agricultural settings [102]. Globally, 44 million people are injured or diseased as a result of contact with animals [3] Dog bites are estimated to account for 76\%-94\% of bite wounds in LMICs [103]. High-risk bite features for which antibiotics should be administered include bites to areas with compromised venous or lymphatic drainage, bites to the hand or a prosthetic joint, bites of patients with diabetes mellitus or who are immunosuppressed, crush injuries, or delayed presentation [104].

Cat bites are the second most common animal bite worldwide, accounting for $2 \%-50 \%$ of bite injuries [103]. Because cat bites tend to be at high risk of secondary infection, antibiotic prophylaxis is recommended, in addition to consideration of the rabies post-exposure prophylaxis, tetanus toxoid, and local wound care necessary for all animal bites [102, 104].

In some settings, monkeys may be responsible for $2 \%-20 \%$ of bites [103]. For certain species of macaque monkeys, the risk of herpes B infection should be considered; this rare virus is nearly uniformly fatal for humans if not treated early [105].

Approximately 5 million snake bites are estimated to occur annually, the majority occurring in Africa and southeast Asia [103]. Infections after a snakebite have been reported to affect $9 \%-35 \%$ of victims $[106,107]$.

\section{Lymphatic filariasis}

Lymphatic filariasis, caused by Wuchereria bancrofti, Brugia malayi, and Brugia timori, affects between 67 to 120 million people worldwide [108,109]. Most of the burden falls on LMICs in Asia, Latin America and the Caribbean, and sub-Saharan Africa [110]. Although acute infection is treated with anti-filarial drugs, chronic stigmata of infection such as hydrocele, lymphedema, and elephantiasis may require operative intervention [109,111,112]. Approximately 37\% of infected personsin historical analyses experienced hydrocele, although this frequency is likely lower today given improved surveillance and treatment [110].

\section{Leishmaniasis}

Infection with Leishmania spp. can cause several clinical syndromes. Cutaneous leishmaniasis, caused by Leishmania tropica, is estimated to affect 0.7 million- 1.2 million persons per year and is an endemic disease in many LMICs [113]. Operative excision of lesions has been used as an adjunct to anti-protozoal treatment [114-116]. Visceral leishmaniasis, also known as kala-azar, is caused by Leishmania donovoni and Leishmania infantum and affects approximately 200,000-400,000 persons per year [113]. Although operative intervention rarely is needed, it has been utilized in cases resistant to, or relapsing from, treatment with anti-protozoal drugs, particularly in immunosuppressed individuals with HIV [117-123].

\section{Noma (gangrenous stomatitis, cancrum oris)}

Noma is rapidly progressive, severe gangrene of the face and mouth commonly caused by a polymicrobial infection including with Fusobacterium necrophorum and Prevotella melaniogenica [124]. This infection typically affects children age three to 10 years living in poverty in sub-Saharan Africa
[124]. In 1998, the WHO estimated that 140,000 children contract noma each year, predominately in a geographic region represented by a belt across western and central Africa [125]. This is likely an underestimation of the true incidence, as fewer than $10 \%$ of affected children seek care during an active infection [126,127]. Most cases $(70 \%-90 \%)$ are fatal [128]. Operative management consists of wound care in the acute phase. In patients who survive the infection, reconstructive surgery may be required.

\section{Healthcare-Associated Infections}

\section{Surgical site infections}

Worldwide, SSIs occur in 2\%-20\% of patients after operation, and the rate differs according to the environment in which operations are performed, local resources, and a number of patient- and surgery-related factors. Rates are likely higher in LMICs, and one study has shown as much as a $20 \%$ SSI rate in women in Africa who have cesarean sections [129].

Surgical site infections are the most common infectious complications among hospitalized patients in developing countries, with a pooled cumulative incidence of 5.6 infections per 100 surgical procedures [130]. The incidence differs depending on the degree of incision contamination. The largest prospective evaluation of SSI after gastrointestinal resection identified 12,539 patients from 343 hospital in 66 countries [131]. The incidence after gastrointestinal resection was lowest among high HICs (9.4\%) and higher among middle-income countries (MICs)(14\%) and low-income countries (LICs) (23\%) [131]. Patients from LICs had the greatest risk of SSI, irrespective of the degree of intraoperative contamination (adjusted odds ratio [AOR] 1.60 [95\% CI 1.05-2.37; $p=0.030]$ ). Furthermore, the African Surgical Outcomes Study noted that infection was the most common post-operative complication, with an overall rate of $10.2 \%(1,156$ of 10,970 patients $)$, and the rate of death linked to infection was $9.7 \%(\mathrm{n}=112)$ [132].

Cesarean section is the most common major surgical operation in many countries, with an estimated 29.7 million performed in 2015 [133,134]. Higher cesarean delivery rates may lead to increases in maternal morbidity and death, as cesarean sections are associated with a five-fold to 20 -fold increase in the risk of infection compared with vaginal delivery [135]. A recent meta-analysis noted that $23.8 \%$ of women dying after childbirth in these settings had had a cesarean section [136]. The rate of SSI after cesarean section differs globally, ranging from $3 \%-11 \%$ in HICs to $3 \%-24 \%$ in LMICs [137-139]. Surgical site infections result in prolonged hospitalization and a greater burden on resourcelimited facilities and environments [133,140]. However, a recent study of post-cesarean SSI rates in four sub-Saharan African countries show results comparable to those in HIC, indicating standardized protocols, peri-operative antibiotics, instrument sterilization, and incision care can be achieved in a low-resource setting [140]. In LMICs, where quality measures are not available or are difficult to assess, post-cesarean SSI could be a proxy for the quality of surgical care.

Variability among the rates of SSI after different surgical procedures and between techniques for the same procedure may not be captured or assessed in these larger crosssectional studies. For example, the weighted, pooled infection rate after appendectomy was $17.9 \%$ in LMIC settings. 
However, in that review, $90 \%$ of appendectomies were performed in an open fashion [13]. Among 6,224 intramedullary nails implanted, infection rates of 3.5\% (CI 3.04.1) and 7.3\% (CI 6.2-8.4) were observed for femoral or tibial fractures, respectively [141]. Pooled analysis of 31 studies from LMICs where mesh was used for inguinal hernia repair identified an infection rate of 4.1\% (CI 2.9-5.4) [142]. The weighted, pooled infection rate after sternotomies in LMICs was $4.3 \%$, which is within the range reported in HIC ecosystems [143]. This similar infection rate after sternotomy may reflect the infrastructure and process management necessary to perform complex cardiac procedures safely, irrespective of the human development index status of a country.

\section{Clostridioides difficile colitis}

Clostridioides difficile is a common cause of gastroenteritis among hospitalized patients and one of the most common causes of health-care-associated infections in the U.S. [144]. Operative intervention is a cornerstone of therapy for severe, fulminant $C$. difficile infection [145]. The burden of these infections in LMICs remains poorly understood, with few national-level estimates [146,147].

\section{Other Infections}

\section{Tuberculosis}

Nearly one quarter of the world's population is infected with, or has been exposed to, Mycobacterium tuberculosis, the causative agent of tuberculosis (TB) [148], with the greatest burden in LMICs $[149,150]$. In 2016, more than 1.7 million deaths were attributable to this infection [148]. Operations may be required for both pulmonary and extrapulmonary TB [151-153]. Operative interventions for pulmonary TB may involve chest tube placement, thoracotomy and decortication, lung resection, or Eloesser flap construction. Operative intervention for multi-drug-resistant pulmonary TB may be cost-effective in LMICs as long as there is adequate surgical expertise, facilities, and diagnostic capacity $[154,155]$. Operative management of extra-pulmonary TB may include biopsy for diagnosis, laparotomy for obstruction or perforation, or spine surgery for Pott's disease.

\section{Empyema}

Empyema may develop as a result of a bacterial or viral pneumonia, TB, retained hemothorax after trauma, or iatrogenic injury. There is no global estimate of the incidence of empyema, although the burden likely is considerable, as lower respiratory tract infections are the leading infectious cause of death worldwide [156]. Pneumococcal and Haemophilus influenzae pneumonia are responsible for more than 99\% of all pneumonia deaths in LMICs $[5,156,157]$. Approximately $20 \%-57 \%$ of patients with bacterial pneumonia will develop a parapneumonic effusion, and of these, 5\%$10 \%$ will progress to frank empyema [158]. Operative interventions may include chest tube placement, thoracotomy and decortication, or Eloesser flap.

\section{Chagas disease}

Chagas disease is caused by the parasite Trypanosoma cruzi, transmitted principally to human beings through bites of the Reduviid bug or through transfusion. An estimated 8 million people are infected with $T$. cruzi worldwide, with most infections occurring in South and Central America [159]. Operation may be indicated in the chronic phase, which can affect the gastrointestinal tract causing megacolon and mega-esophagus (10\% of infected patients) or the heart, resulting in dilated cardiomyopathy (30\%) [160-162].

\section{Rheumatic heart disease}

Group A streptococcal infection can lead to rheumatic fever, which can in turn cause rheumatic heart disease. The disease is characterized by autoimmune-mediated, progressive heart valve damage, which can lead to cardiac failure [163]. The mitral valve is most commonly affected [164]. Rheumatic heart disease is estimated to affect 15.6-33.4 million people worldwide, with most of these infections occurring in LMIC [165]. Operative therapeutic options are mitral commissurotomy, valve repair, or valve replacement [164].

\section{The Surgical Ecosystem}

Not only are comprehensive surgical infection data lacking, existing data on available surgical workforce and capacity are limited and fragmented, particularly in LMICs. According to the best estimates, 5 billion persons lack access to timely and safe surgical care [166]. This crisis is magnified in LMICs, where two thirds of the poorest countries are the site of only $6.5 \%$ of all operations performed [167]. The global number and distribution of surgical providers remain poorly assessed [168]. Efforts to build a WHO surgical workforce database to quantify surgical providers by country is in progress [169]. Worldwide, there are an estimated 1.1 million specialist surgeons, approximately 550,000 anesthesiologists, and 480,000 obstetricians, with only $20 \%$ of this workforce (19\% surgeons, 15\% anesthesiologists, $29 \%$ of obstetricians) working in LMICs [169]. Providers included in this database exclude trained non-physician personnel, which can underestimate the available surgical workforce, as task shifting is more common in LMICs. However, there is no standardized training of non-physician providers and limited data to show safety and effectiveness. Continuous data collection over the time of the surgical specialist workforce will assist in strengthening surgical systems on a local, national, and international scale.

To manage surgical infections adequately, one needs to consider the full spectrum of the healthcare workforce. Multidisciplinary support from physicians in infectious disease and other specialties, if available, can enhance patient care greatly. There needs to be adequate nursing staff, as good nursing care is essential for the care of operative sites. Ancillary support, such as physical therapists, nutritionists, and social workers, also plays invaluable roles in postoperative recovery. Ideally, there should be a laboratory with staff capable of culturing bacterial pathogens and testing them for sensitivity. This allows creation of an evidencebased antibiogram and an understanding of local microbiology susceptibility patterns. The previously cited prospective gastrointestinal surgery study noted that when such services were available to test incision flora, $36 \%$ of cultures identified microbes that were resistant to the antibiotic used for preoperative prophylaxis at that location7 [131]. 


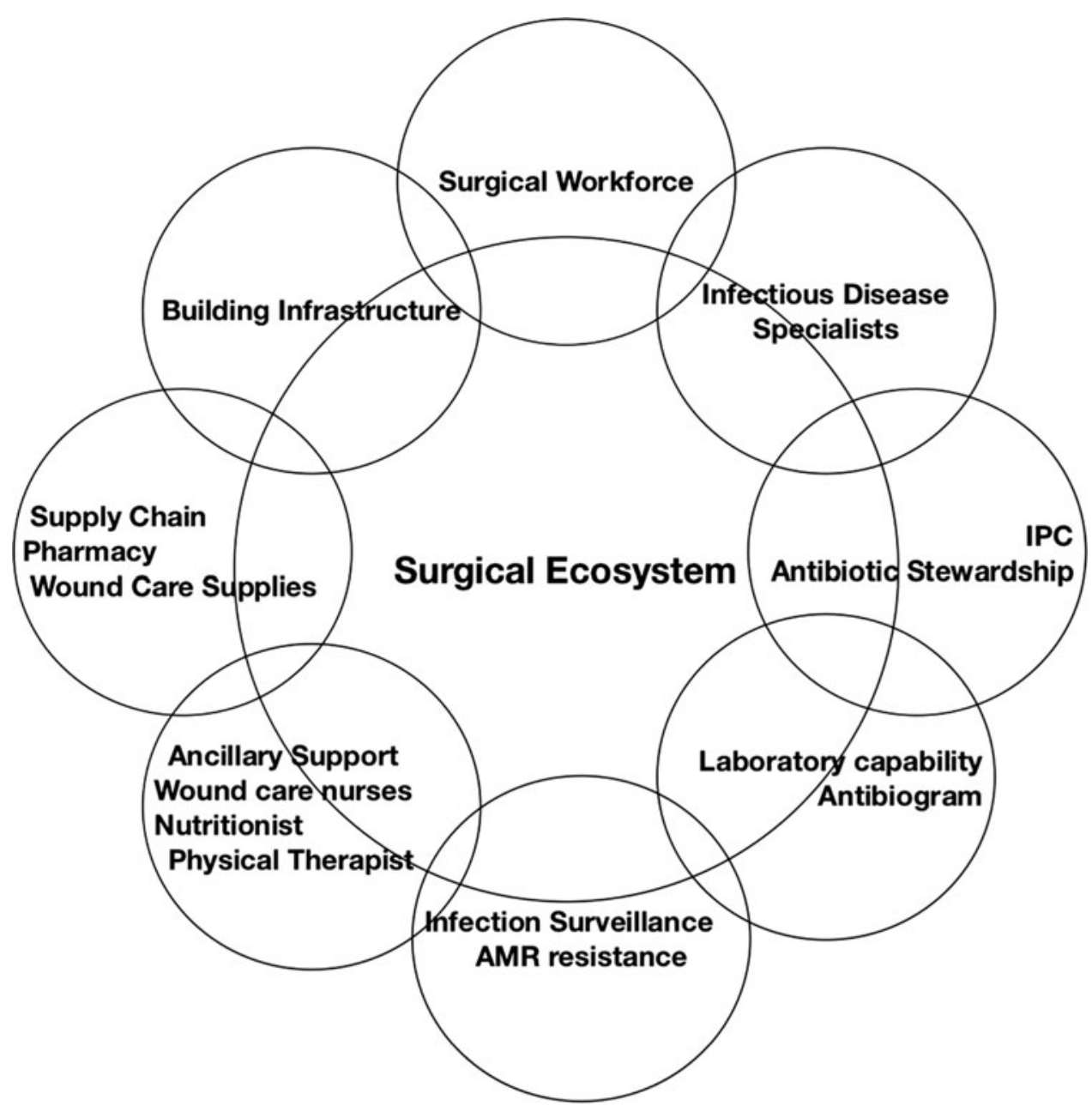

FIG. 2. Surgical ecosystem.

A growing surgical workforce and appropriate distribution of that workforce are components of increasing surgical capacity. Devries and Rosenberg conceptualize surgery as an ecosystem that involves a network of persons, processes, and materials necessary for rendering surgical services in a local environment (Fig. 2) [170]. Thus, a functional effective surgical ecosystem not only includes the availability of healthcare providers, but integration of related subsystems such as building infrastructure (electricity, waste management), biomedical engineering, supply chains, and pharmacy [170]. The ecosystem model and investment in surgical systems can improve care across all surgical domains and specialties, including surveillance and management of surgical infections globally. This requires continuing surveillance of infections, antibiotic use, laboratory capabilities, and site care materials plus local and national champions to institute educational training modules to improve stewardship.

One under-recognized aspect of surgical infection management is the availability of materials and local protocols for incision management. Supply chain and resource challenges for gauze, tape, saline, and other dressing supplies can impact incision management. The recent WHO Guidelines on SSI prevention make conditional recommendations on the use of negative- pressure wound therapy (NPWT) and other ad- vanced dressings [171]. Use of NPWT has the potential to improve management of incisions through its wicking of excess fluid, barrier effect on wards with high cross-over infectious risk, and ease of management.

\section{Antibiotic Use, Availability, and Resistance}

Surgical infections are treated by a combination of operative intervention and antibiotics, depending on the underlying pathology. The scientific community has fought for focused and logical use of antibiotics for many years [172]. Some $20 \%-50 \%$ of antibiotic usage in acute care models is either unnecessary or inadvertent, which risks longer hospital stays and drug resistance [173]. In the U.S., overuse of antibiotics results in 23,000 deaths and costs $\$ 20$ billion per year. Increased costs can be secondary to a requirement for more expensive treatment options, delayed hospital discharge, or delayed administration of appropriate antibiotics [174].

Antimicrobial resistance (AMR) in bacteria is driven largely by antibiotic overuse in institutional environments. Antibiotic misuse is rampant throughout the world. This problem is especially problematic in LMICs, as these areas are particularly vulnerable to the economic implications of 
adverse events related to antibiotics and large-scale AMR and where stewardship might be particularly challenging [175]. In LMICs, only $70 \%$ of patients with pneumonia receive appropriate antibiotics, and half of those with viral upper respiratory tract infections receive antibiotics inappropriately [176]. In addition to over-prescribing by healthcare workers, antibiotics may be available over the counter, allowing more prolific community access. There also may be variability in access to antibiotics, forcing providers to change antibiotics continually before treatment is completed, which can lead to resistance. The issue of overuse of antibiotics also has plagued the livestock industry [177]. Animal waste as well as unregulated pharmaceutical waste contribute to resistance; humans are exposed to these antibiotic-resistant bacteria through poor hygiene and contract with contaminated water.

Resistant organisms are classified as multi-drug resistant (MDR), resistant to three or more categories of agents; extensively drug-resistant (XDR), susceptible to only one or two categories of antimicrobial agents; and pan-drug resistant (PDR), susceptible to no category of antimicrobial agents. Patients receiving antibiotics are at a higher risk of becoming colonized with MDR bacteria. Carbapenems and polymyxins are antibiotics of choice for the treatment of MDR gramnegative bacteria [178]. The latest literature shows greater usage of these last-line agents, suggesting a higher incidence of extended spectrum beta-lactamase-producing organisms, XDR, and PDR organisms around the globe $[179,180]$. Carbapenem- and third-generation cephalosporin-resistant Enterobacteriaceae are an area of critical priority [180].

The growing crisis of AMR is widespread, with much of the data coming from HICs [181]. Drug-resistant infections account for 50,000 deaths yearly in Europe and the United States with an estimated 10 million deaths forecast to occur worldwide by the year 2050, with the majority of deaths predicted to be in LMICs [182]. Despite the dearth of data from LMICs, the existing data demonstrate high rates of AMR. Nosocomial and hospital-associated infections (HAIs) are reported increasingly in LMICs, with studies finding twice the average prevalence compared with Europe and three times the rate in intensive care units compared with the rates in the United States [130]. Emergence of common drug-resistant infections such as methicillin-resistant Staphylococcus aureus (MRSA), vancomycin-resistant Enterobacteriaceae (VRE), and multidrug-resistant gram-negative bacteria are increasing in LMICs and are most pronounced within LMIC intensive care units [183]. In addition, there is increasing nosocomial transmission of community-acquired multi-drug-resistant organisms such as Streptococcus pneumoniae, M. tuberculosis, Salmonella spp., Shigella spp,, and Vibrio cholerae [184]. The WHO has identified critical resistant bacteria that warrant priority research and new antibiotic development: carbapenem-resistant Acinetobacter baumannii and Pseudomonas aeruginosa, carbapenem-resistant and third-generation cephalosporinresistant Enterobacteriaceae, vancomycin-resistant Enterococcusfaecium, MRSA, clarithromycin-resistant $H$. pylori, and fluoroquinolone-resistant Campylobacter, Salmonella spp., Neisseria gonorrhoeae, S. pneumoniae, Haemophilus influenzae, and Shigella spp. [185]. The burden of these pathogens in LMICs is particularly worrisome because of the lack of alternative treatment options, limited ability to identify these organisms without adequate laboratory support, and inability to perform antimicrobial susceptibility testing [186]. Surveillance is largely lacking in LMICs, although active measures have been taken to track drug-resistant tuberculosis, malaria, and HIV [187]. Rising AMR transmission in LMICs is compounded by increasing population density, lack of access to clean water, poor sanitation practices, inadequate healthcare infection control, and increased susceptibility to infection because of malnutrition or HIV infection [186]. Despite the bulk of communicable diseases being present in LMICs, those countries typically have the least resources to tackle the problem, with weaker surveillance systems. Therefore, the largest number of lives lost and the enormous economic burden from drug-resistant infections are predicted to be in LMICs $[183,188]$.

The establishment of antimicrobial stewardship programs - coordinated efforts to improve appropriate antimicrobial usage, including prescription of the optimal agent, dose, and duration of therapy - is an important global strategy to decrease antimicrobial use and resistance. In high-income areas, these programs have shown success in reducing resistance, lowering costs, and improving overall care [189]. Individual instances of stewardship in LMICs have been successful. For example, one Doctors Without Borders surgical program for victims of war in Amman, Jordan, Iraq, Yemen, and Syria demonstrated that implementation of a stewardship program in areas with a significant lack of resources resulted in a cost reduction of $\$ 160,000$ and overall decreased broadspectrum antibiotic use [190]. The intervention included a team that reviewed hospital prescriptions and made recommendations to optimize the choice of treatment, duration, and route [190].

Challenges to establishment of antimicrobial stewardship programs include variable access to antibiotics, limited data on local resistance patterns, cultural and organizational differences, and cost loaded on top of loco-regional variation in organism representation and resistance patterns. In addition, a majority of antibiotics in LMICs are prescribed in the community [191]. Strategies that need to be employed in the this setting include improving knowledge of the medical staff, pharmacy workers, and public regarding treatment guidelines and appropriate antibiotics and adjusting the inventory of antibiotics. This teaching should start at the medical student or undergraduate level [191].

Future interventions also may display unpredictable geographic variations, such as efforts targeting at restoring a healthy microbiome and host immune defense modulation. Finally, with the increasing frequency of global travel and medical tourism, increasingly robust methods to track the spread of resistant organisms will become ever more necessary.

\section{Measurements and Indicators}

Measurement is the cornerstone of improvement; without a contemporaneous understanding of outcomes, improvement becomes impossible. The classic strategy for measurement is described in the Donabedian framework of structure, process, and outcome, where structure relates to the resources available within the system of care, process refers to the practices that contribute to the delivery of care, and outcomes are the results of care [192]. A number of indicators can improve a facility's understanding of its results and direct improvement opportunities (Table 2). These indicators are ideally suited 
Table 2. Measurement and Surveillance Recommendations

\begin{tabular}{lll}
\hline Indicator & Type & \multicolumn{1}{c}{ Source of Information } \\
\hline $\begin{array}{l}\text { Surgical providers with infection expertise } \\
\text { Antibiotic availability } \\
\text { Timing and duration of prophylactic antibiotics }\end{array}$ & $\begin{array}{l}\text { Structure } \\
\text { Structure } \\
\text { Process }\end{array}$ & $\begin{array}{l}\text { Hospital with IPC team and surgeon involved } \\
\text { Pharmacy inventory and purchase log } \\
\text { Operative and anesthetic logs, nursing notes, other } \\
\text { surveillance mechanisms }\end{array}$ \\
$\begin{array}{l}\text { Incision care protocol } \\
\begin{array}{l}\text { Microbiology laboratory with } \\
\text { culture and sensitivity capacity }\end{array}\end{array}$ & $\begin{array}{l}\text { Process } \\
\text { Structure }\end{array}$ & $\begin{array}{l}\text { Protocol availability } \\
\text { Microbiology laboratory review }\end{array}$ \\
$\begin{array}{l}\text { Infection prevention and control program } \\
\text { Infection rate }\end{array}$ & $\begin{array}{c}\text { Structure } \\
\text { Outcome }\end{array}$ & $\begin{array}{c}\text { IPC team established at site } \\
\text { Hospital logs, ideally with some risk stratification (such as } \\
\text { incision classification) }\end{array}$ \\
\hline
\end{tabular}

IPC $=$ Infection Prevention and Control.

for facility-level collection; however, they also can be used in aggregate nationally to aid with policies that could improve surgical capacity, delivery, and outcomes.

Although outcomes are clearly of tremendous value, understanding the system and the processes of care also are useful, particularly when attempting to value and incentivize improvements at the facility level. Some structural measures can be achieved quickly, whereas others will be a greater challenge. One important structural characteristic of a facility is the presence of an Infection Prevention and Control (IPC) committee that takes responsibly and maintains oversight of infections and quality control mechanisms within a hospital, clinic, or health system [193]. Such a committee can audit processes of care, particularly as they pertain to perioperative antibiotic use and infection control practices (such as sterilization of instruments and surgical equipment, preoperative bathing, and skin and hand preparation). They also can impact practice, especially when leading surgeons participate in such a group, as the misuse of antibiotics in the peri-operative and post-operative period is a major source of potential harm; these practices, often are engrained during training, founded on misconceptions of how antimicrobial drugs work, and require continuing education and oversight to bring practices into line with accepted standards. The presence of a microbiology unit or a laboratory that can perform cultures and sensitivity testing is an important aspect of IPC. Knowing what organisms are responsible for infection and the local AMR patterns is critical for selection of appropriate antibiotics. By the same token, knowing what antibiotics are available to the surgeons for both prophylaxis and treatment-coupled with an understanding of community and hospital resistance patterns - allows a facility and its IPC team to use antimicrobial resources effectively and efficiently. This usually cam be understood through pharmacy inventories, purchasing history, and supply logs.

The early use of broad-spectrum antibiotics in patients presenting with sepsis is well established [194]. Administering empiric, broad-spectrum antimicrobial therapy within one hour of presentation when there are signs of sepsis or septic shock, coupled with the narrowing of therapy once a pathogen is identified, is best practice. For patients presenting with an intra-abdominal infection, once source control has been established definitively, antibiotics can be discontinued safely after four days [195].

The timing, selection, and duration of antibiotics present a tremendous opportunity for improvement. According to the
WHO Guidelines on SSI Prevention, surgical antibiotic prophylaxis should be administered within 120 minutes of skin incision [196]; in fact, many authorities have recommended that antibiotics be delivered within 60 minutes to take advantage of peak tissue concentrations after intravenous administration [197]. For practical purposes, this frequently means antibiotic delivered either in the immediate pre-operative period or once the patient arrives in the operating room. Antibiotic selection should be guided by the type of operation, the likely contaminant (skin, gut flora, etc), and resistance patterns in both the community and the hospital [198,199].

Infection prevention and control efforts frequently are disconnected from the circumstances of surgical care and occur without the input of surgeons. As surgical providers contribute to these committees, understanding whether and how they participate, and promoting their training in surgical infection control principles, can help strengthen local priorities to reduce peri-operative infections and advance surgical outcome surveillance systems. Surgical involvement in IPC activities must be encouraged and IPC expertise leveraged on behalf of surgeons working to improve the quality and safety of surgical care.

There is a wide range of outcomes to monitor at both the patient and the facility level. The peri-operative mortality rate (POMR) has been suggested as a global surgical indicator. Other potential measures are length of hospital stay, SSI rate, and AMR.

The current definition of SSI comes from the Centers for Disease Control (CDC), which defines superficial, deep, and organ space infections [200]. These definitions can be cumbersome, as diagnosis by a physician frequently is the default in the absence of other clinical signs. More objective criteria have been applied in large studies, particularly when trying to compare different settings, such as the GlobalSurg II study assessing SSI rates for gastrointestinal surgery across 343 hospitals in 66 countries [131]. Such criteria include: (1) Purulent drainage from the superficial or deep incision; (2) pain/tenderness, localized swelling, redness, heat, or fever and that the incision is opened deliberately or dehisces spontaneously; or (3) abscess within the incision [201]. This is a practical and practicable definition that relies on purely objective criteria. Such practical definitions capture clinically meaningful morbidity, as drainage, purulent effluent, incisions that have opened, and abscesses all require additional care and add to the length of stay and cost. Organ-space 
infections, the most challenging to diagnose and treat, still defy easy assessment without the use of imaging, something that can be prohibitively expensive in many settings. Even in HICs, such infections usually require the maturation of an abscess rind in order to distinguish free edematous fluid or old blood from actual infection or clinical deterioration that drives surgical or other invasive intervention regardless of imaging findings.

\section{Solutions and Interventions}

\section{Reduce the burden of surgical infections}

There many preventive and treatment options to reduce the burden of the wide global range of surgical infections. Clean water and sanitation can prevent typhoid fever transmission, and its early recognition and treatment may prevent intestinal perforation. Vaccination can stop the spread of hepatitis B and $\mathrm{C}$ and progression to HCC. Helicobacter pylori and peptic ulcer disease can be treated with triple therapy and managed long term with proton pump inhibitors and histamine blockers. Preventive maintenance of patients with diabetes can prevent or delay the onset of peripheral neuropathy and diabetic foot infections. Early fracture immobilization, fracture reduction, and wound irrigation can reduce disability and infections such as osteomyelitis that can be associated with open fractures [202].

Much literature has been dedicated to the prevention and management of SSIs. Environmental and resource factors include availability of surgical site preparation, hand washing techniques, pre-operative antibiotics, infection surveillance, incision management systems, and peri-operative serum glucose control. Patient and surgical factors include body mass index (BMI), diabetes, cardiopulmonary disease, length of operation, blood loss, degree of contamination, and location of the operation. Reducing the incidence of SSIs leads to significant clinical improvements for patients, cost savings, and reduced hospital lengths of stay. In recent WHO guidelines for SSIs, 29 recommendations are made based on the most recent evidence [196]. Although some of these guidelines are not readily deliverable in LMICs, many others are achievable.

Patient education and participation have been promoted in medication management in recent years. In 2017, a group of infection prevention and infectious disease experts convened to review how current evidence could be conveyed to patients to increase their participation and in turn reduce SSI rates [203]. The experts produced nine recommendations ranging from S. aureus decolonization, to personal hygiene measures pre-operatively and post-operatively, to management of diabetes mellitus. Patient participation can be an especially high-yield concept in LMICs, where patients often live remote from hospitals and health centers. Engaging key stakeholders, such as Ministries of Health, is critical to ensuring program sustainability.

\section{Improve surveillance of surgical infections}

Lack of personnel and money is one of the major obstacles to compiling reliable surveillance data when paper forms are used and hospitals do not have electronic health records. Automated data capture and central deposition may be particularly advantageous for review and analysis. Research
Electronic Data Capture (REDCap) is one useful application for wide-scale projects [204]. "Store and forward" data collection is especially important when collecting data in areas where internet access is limited [204].

Establishing national databases with hospitals and health centers enrolling in the programs voluntarily may improve surveillance. One such effective and thoughtful approach emerged in Thailand in 2009 where 10 hospitals enrolled [205]. A central headquarters for recording data on one computer was established at each study site, and a form, manual, and website were created to guide each of the sites. Key aspects that led Thai investigators to enroll almost 18,000 patients was their commitment to follow-up and access given to individual hospitals. Quarterly centralized meetings were provided for discussion and instruction, to review definitions, and to analyze data. Researchers visited each site every two to three months and were available continuously via telephone or e-mail throughout the study period. Furthermore, researchers allowed hospitals to compare their SSI data with the pooled dataset from the other nine hospitals. Surveillance tends to improve care and outcomes, so it is not surprising that all hospitals had a decrease in SSI rates during the period.

Further opportunities for improving surveillance will involve education of healthcare providers, patients, and families. Many SSIs appearing after discharge may be missed in existing surveillance programs. Novel studies are examining the role of smartphones and mHealth technology to identify and track outcomes including surgical infections [206].

\section{Improve antibiotic use and stewardship}

The first goal to improve use of antibiotics should be to track how often they are used. Antibiotic surveillance should occur in parallel with surveillance of surgical infections, and information should be recorded through establishment of a centralized registry or use of advanced database tools. The following information should be recorded: Antimicrobial agents used, dose, route of administration, duration of use, and organisms treated (whether cultured or presumptively diagnosed). When it is available in LMIC locations, thoroughly recording microbiologic culture data is important to assess the appropriateness of antibiotic use. A team should be created to evaluate antibiotic use. In conjunction with available data on bacteriology and AMR patterns, the team should help develop a tool to optimize antibiotic selection.

The next goal should be to establish country or regionally based antibiotic stewardship programs (ASPs). Such programs are still fairly new even to HICs, with most started in the last decade. Much of the early progress in establishing ASPs will be recording data on antibiotic use and duration as it relates to the microbiology or diagnosed SSIs (Table 3). The concepts of a dedicated team to start an ASP, record data, and manage improvement projects have been described in the literature for environments with better resources [207].

Although an ASP program may not be feasible in all settings, concepts of antibiotic stewardship should be stressed in LMICs. Education should be the cornerstone to improving antibiotic stewardship and to achieving optimal effects, should not be purely passive; e.g., using just written materials and lectures [208]. The highest yield in making gains in antibiotic stewardship may necessitate earlier education 
Table 3. Key Questions for Establishing Antibiotic Stewardship Programs

Were tissue, fluid, or blood cultures done; and what were the results?

What was the most important aspect of management of the surgical site infection? Incision and drainage, irrigation, dressing care, or the antibiotics?

Were antibiotics given in line with local guidelines or microbial patterns?

Were antibiotics switched from intravenous to oral when possible?

Is there a restricted set of antibiotics that require preapproval from a specialist with infectious disease or surgical infection training?

Was therapeutic drug monitoring done?

programs, starting in medical, pharmacy, and nursing schools. Little curriculum has been devoted to antibiotic stewardship in more resourced areas of the world yet $90 \%$ of medical students suggest a need for more education on the topic [209]. Recruiting well-regarded surgeons to lead this work helps reassure other clinicians that best practices involve more judicious and selective use of antibiotics.

\section{Improve management of surgical infections}

Improvements in the management of surgical infection can be achieved through early recognition. Once infections are recognized, management often requires simple straightforward surgical principles including source control, dressing care, thoughtful antibiotic courses, and diligent followup. Improving early recognition involves concepts similar to those described above regarding surveillance. Surgeons in LMICs often have significantly greater workloads because of shortages of trained colleagues and provide care for a larger number of patients over wider geographic regions. An outreach program allows specialists, such as orthopedists, who often are more centrally located in the major cities, to come to the primary-level hospitals on a weekly or monthly basis to perform cases while educating general practitioners on open fracture management. Increasing the training of surgeons is a valuable step to increase the number of specialists within a country, although this is costly and takes time. An alternative is to train general practitioners, nurses, and health center workers on the signs and symptoms of surgical infections. Technology to improve communication between outpatient providers and surgeons also may help improve early recognition of surgical infections.

Increasing health center workers' capacity in LMICs through education programs establishing them as a local experts improves management of a number of disease processes including HIV, hypertension, adolescent care, and chronic kidney disease [210-212]. By engaging in serial, frequent training sessions of health center workers, marked improvements can be made in earlier recognition and treatment of surgical infections [206]. The goals for health center workers are to establish skill sets to recognize superficial SSIs and appropriate site care. Additionally, health center workers should be trained to recognize signs and symptoms of common surgical conditions including peritonitis, obstruction, and soft tissue infections. Education on common postoperative complications requiring operation, such as deep incisional and organ space infections, will identify patients needing prompt referral to a facility with surgical capabilities. Lastly, training should include appropriate indications for and usage of antibiotics. Training and education principles can be applied to general practitioners, healthcare workers, nurses, and pharmacists in both inpatient and outpatient settings so that surgical infections are embraced as a multidisciplinary problem that all providers are stakeholders in. Ideally, training will be conducted in local environments, ensuring that providers are able to apply the principles using local resources. Training and education programs also should include methods to monitor retention of knowledge and skills.

Large gains can be achieved by mobilization and education of personnel, including surgeons, nurses, operating room technicians, hospital staff, and patients. Regardless of which guidelines are chosen on the basis of available local resources, we suggest a bi-annual educational program of institutional guidelines, with the program materials delivered to all providers involved in the care of surgical patients. A biannual schedule would allow updates in evidence to be discussed. Adherence to institutional guidelines should be monitored over intervals and compared with surveillance data on the rates of surgical infections during the same intervals. Future directions can involve technology to allow collaborative education programs between institutions in LMICs. This could improve efficiency of content delivery, as programs could be conducted in regions that have similar resources and surgical diseases. There also is an opportunity for HICs to engage with LMICs in this fashion.

\section{Conclusion}

Surgical infections constitute a large burden of disease globally, with a significant burden carried by LMICs. Challenges to management in LMICs include a shortage of trained personnel and material resources. The increasing rate of AMR, likely related to antibiotic misuse, adds additional challenges. Development of surveillance, infection prevention, and antimicrobial stewardship programs are initial steps forward. Education is critical and should begin early in training, be an active process, and be sustained through biannual educational programs.

\section{Author Disclosure Statement}

The authors have no disclosures or conflicts of interest to report.

This research did not receive any specific grant from funding agencies in the public, commercial, or not-for-profit sectors.

\section{References}

1. World Health Organization. Important Issues in the Approach to Surgical Site Infection Prevention: Global Guidelines for the Prevention of Surgical Site Infection. Geneva: World Health Organization, 2016.

2. Ozgediz D, Jamison D, Cherian M, McQueen K. The burden of surgical conditions and access to surgical care in low- and middle-income countries. Bull World Health Organ 2008;86:646-647.

3. Global Burden of Disease Program. Global Health Data Exchange 2019. Available at: http://ghdx.healthdata.org/ gbd-results-tool Accessed 20 February 2019. 
4. Lozano R, Naghavi M, Foreman K, et al. Global and regional mortality from 235 causes of death for 20 age groups in 1990 and 2010: A systematic analysis for the Global Burden of Disease study 2010. Lancet 2012;380: 2095-2128.

5. Murray CJ, Vos T, Lozano R, et al. Disability-adjusted life years (DALYs) for 291 diseases and injuries in 21 regions, 1990-2010: A systematic analysis for the Global Burden of Disease study 2010. Lancet 2012;380:21972223.

6. Ferris M, Quan S, Kaplan BS, et al. The global incidence of appendicitis: A systematic review of population-based studies. Ann Surg 2017;266:237-241.

7. Zoguereh DD, Lemaitre X, Ikoli JF, et al. [Acute appendicitis at the National University Hospital in Bangui, Central African Republic: Epidemiologic, clinical, paraclinical and therapeutic aspects](Fre). Santé (Montrouge, France) 2001;11:117-125.

8. Ohene-Yeboah M, Abantanga FA. Incidence of acute appendicitis in Kumasi, Ghana. W Afr J Med 2009;28: 122-125.

9. Ahmed S, Makama J, Mohammed U, et al. Epidemiology of appendicitis in Northern Nigeria: A 10-year review. Sub-Saharan Afr J Med 2014;1:185-190.

10. Horntrich J, Schneider W. [Appendicitis from an epidemiological viewpoint] (Ger). Zentralbl Chir 1990;115: 1521-1529.

11. Yang E, Kahn D, Cook C. Acute appendicitis in South Africa: A systematic review. S Afr J Surg 2015;53:31-38.

12. Kong VY, Bulajic B, Allorto NL, et al. Acute appendicitis in a developing country. World J Surg 2012;36:2068-2073.

13. Foster D, Kethman W, Cai LZ, et al. Surgical site infections after appendectomy performed in low and middle human development-index countries: A systematic review. Surg Infect 2018;19:237-244.

14. Findlay JM, Kafsi JE, Hammer C, et al. Nonoperative management of appendicitis in adults: A systematic review and meta-analysis of randomized controlled trials. J Am Coll Surg 2016;223:814-824

15. Stinton LM, Shaffer EA. Epidemiology of gallbladder disease: Cholelithiasis and cancer. Gut Liver 2012;6:172-187.

16. Sartorius B, Sartorius K, Taylor M, et al. Rapidly increasing body mass index among children, adolescents and young adults in a transitioning population, South Africa, 2008-15. Int J Epidemiol 2018;47:2099.

17. Lao XQ, Ma WJ, Sobko T, et al. Dramatic escalation in metabolic syndrome and cardiovascular risk in a Chinese population experiencing rapid economic development. BMC Public Health 2014;14:983.

18. Hooi JKY, Lai WY, Ng WK, et al. Global prevalence of Helicobacter pylori infection: Systematic review and meta-analysis. Gastroenterology 2017;153:420-429.

19. Peleteiro B, Bastos A, Ferro A, Lunet N. Prevalence of Helicobacter pylori infection worldwide: A systematic review of studies with national coverage. Dig Dis Sci 2014;59:1698-1709.

20. Zhang XY, Zhang PY, Aboul-Soud MA. From inflammation to gastric cancer: Role of Helicobacter pylori. Oncol Lett 2017;13:543-548.

21. Crew KD, Neugut AI. Epidemiology of gastric cancer. World J Gastroenterol 2006;12:354-362.

22. Stewart B, Khanduri P, McCord C, et al. Global disease burden of conditions requiring emergency surgery. $\mathrm{Br} \mathrm{J}$ Surg 2014;101:e9-e22.
23. Lavanchy D. Hepatitis B virus epidemiology, disease burden, treatment, and current and emerging prevention and control measures. J Viral Hepatitis 2004;11:97-107.

24. Ott JJ, Stevens GA, Groeger J, Wiersma ST. Global epidemiology of hepatitis B virus infection: New estimates of age-specific $\mathrm{HBsAg}$ seroprevalence and endemicity. Vaccine 2012;30:2212-2219.

25. MacLachlan JH, Cowie BC. Hepatitis B virus epidemiology. Cold Spring Harbor Persp Med 2015;5:a021410.

26. Zampino R, Boemio A, Sagnelli C, et al. Hepatitis B virus burden in developing countries. World J Gastroenterol 2015;21:11941-11953.

27. Franco E, Bagnato B, Marino MG, et al. Hepatitis B: Epidemiology and prevention in developing countries. World J Hepatol 2012;4:74-80.

28. Mohd Hanafiah K, Groeger J, Flaxman AD, Wiersma ST. Global epidemiology of hepatitis $\mathrm{C}$ virus infection: New estimates of age-specific antibody to HCV seroprevalence. Hepatology 2013;57:1333-1342.

29. El-Serag HB. Epidemiology of viral hepatitis and hepatocellular carcinoma. Gastroenterology 2012;142:12641273.

30. Lemoine M, Thursz MR. Battlefield against hepatitis B infection and HCC in Africa. J Hepatol 2017;66:645-654.

31. Ruiz E, Rojas Rojas T, Berrospi F, et al. Hepatocellular carcinoma surgery outcomes in the developing world: A 20-year retrospective cohort study at the National Cancer Institute of Peru. Heliyon 2016;2:e00052.

32. Mak D, Babb de Villiers C, Chasela C, et al. Analysis of risk factors associated with hepatocellular carcinoma in black South Africans: 2000-2012. PloS One 2018;13: e0196057.

33. Kew MC. Epidemiology of hepatocellular carcinoma in sub-Saharan Africa. Ann Hepatol 2013;12:173-182.

34. Crump JA, Luby SP, Mintz ED. The global burden of typhoid fever. Bull World Health Organ 2004;82:346-353.

35. Buckle GC, Walker CL, Black RE. Typhoid fever and paratyphoid fever: Systematic review to estimate global morbidity and mortality for 2010. J Global Health 2012;2:010401.

36. Als D, Radhakrishnan A, Arora P, et al. Global trends in typhoidal salmonellosis: A systematic review. Am J Trop Med Hyg 2018;99:10-19.

37. Mogasale V, Desai SN, Mogasale VV, et al. Case fatality rate and length of hospital stay among patients with typhoid intestinal perforation in developing countries: A systematic literature review. PloS One 2014;9:e93784.

38. Mavilia MG, Molina M, Wu GY. The evolving nature of hepatic abscess: A review. J Clin Transl Hepatol 2016;4: $158-168$.

39. Huang CJ, Pitt HA, Lipsett PA, et al. Pyogenic hepatic abscess: Changing trends over 42 years. Ann Surg 1996; 223:600-607.

40. Lee KT, Wong SR, Sheen PC. Pyogenic liver abscess: An audit of 10 years' experience and analysis of risk factors. Dig Surg 2001;18:459-465.

41. Pang TC, Fung T, Samra J, et al. Pyogenic liver abscess: An audit of 10 years' experience. World J Gastroenterol 2011;17:1622-1630.

42. Walsh JA. Problems in recognition and diagnosis of amebiasis: Estimation of the global magnitude of morbidity and mortality. Rev Infect Dis 1986;8:228-238.

43. Ximenez C, Moran P, Rojas L, et al. Reassessment of the epidemiology of amebiasis: State of the art. Infect Genet Evol 2009;9:1023-1032. 
44. Ellyson JH, Bezmalinovic Z, Parks SN, Lewis FR Jr. Necrotizing amebic colitis: A frequently fatal complication. Am J Surg 1986;152:21-26.

45. Adams EB, MacLeod IN. Invasive amebiasis I: Amebic dysentery and its complications. Medicine 1977;56:315323.

46. Chen WJ, Chen KM, Lin M. Colon perforation in amebiasis. Arch Surg 1971;103:676-680.

47. Haque R, Huston CD, Hughes M, et al. Amebiasis. N Engl J Med 2003;348:1565-1573.

48. Knobloch J, Mannweiler E. Development and persistence of antibodies to Entamoeba histolytica in patients with amebic liver abscess: Analysis of 216 cases. Am J Trop Med Hyg 1983;32:727-732.

49. Craig PS, McManus DP, Lightowlers MW, et al. Prevention and control of cystic echinococcosis. Lancet Infect Dis 2007;7:385-394.

50. Crompton DW. Ascaris and ascariasis. Adv Parasitol 2001;48:285-375.

51. Ramareddy RS, Alladi A, Siddapa OS, et al. Surgical complications of Ascaris lumbricoides in children. J Indian Assoc Pediatr Surg 2012;17:116-119.

52. Sharma A, Jariwala P, Kaur N. Biliary ascariasis presenting with gangrenous perforation of the gall bladder: Report of a case and brief review of literature. Trop Doctor 2018;48:242-245.

53. Thakur S, Jhobta A, Thakur CS. Adult small gut intussusception caused by ascaris as a lead point. Am J Trop Med Hyg 2015;93:205-206.

54. Darlington CD, Anitha GFS. Ascaridial volvulus: An uncommon cause of ileal perforation. Iran J Med Sci 2018;43:432-435.

55. Centers for Disease Control and Prevention. Shistosomiasis 2018, Available at: https://www.cdc.gov/parasites/ schistosomiasis/index.html Accessed August 28, 2018.

56. Majrashi SA, Al Amoodi OM. Schistosomiasis as a cause of acute cholecystitis. Saudi Med J 2018;39:725-728.

57. Sood R, Green MR, McKeever PA, Johnstone JM. Meckel's diverticulitis associated with Schistosoma mansoni. J Pediatr Gastroenterol Nutr 1999;28:336-337.

58. Jonas L, Bombil I, Mannell A. Unusual histopathologies of the appendix. S Afr J Surg 2017;55:55-56.

59. Dincel O, Goksu M, Turk BA, et al. Incidental findings in routine histopathological examination of appendectomy specimens: Retrospective analysis of 1970 patients. Indian J Surg 2018;80:48-53.

60. Mostafa MH, Sheweita SA, O'Connor PJ. Relationship between schistosomiasis and bladder cancer. Clin Microbiol Rev 1999;12:97-111.

61. Ferraz AA, Bacelar TS, Silveira MJ, et al. Surgical treatment of schistosomal portal hypertension. Int Surg 2001;86:1-8.

62. Da Silva LC. Portal hypertension in schistosomiasis: Pathophysiology and treatment. Memor Instit Oswaldo Cruz 1992;87(Suppl 4):183-116.

63. Ede CJ, Nikolova D, Brand M. Surgical portosystemic shunts versus devascularisation procedures for prevention of variceal rebleeding in people with hepatosplenic schistosomiasis. Cochrane Database System Rev 2018;8: Cd011717.

64. Hong ST, Fang Y. Clonorchis sinensis and clonorchiasis: An update. Parasitol Int 2012;61:17-24.

65. Fujiya K, Ganno H, Ando M, Chong JM. Clonorchis sinensis ova in bile juice cytology from a patient with se- vere hyperbilirubinemia and portal vein thrombosis. Diagn Cytopathol 2016;44:223-225.

66. Hao Y, Bao W, Jin M, et al. Painless jaundice caused by Clonorchis sinensis infection: A case report. Korean J Parasitol 2016;54:323-327.

67. Lim JU, Joo KR, Shin HP, et al. Obstructive jaundice caused by clonorchiasis-associated duodenal papillitis: A case report. J Korean Med Sci 2011;26:135-137.

68. Stunell H, Buckley O, Geoghegan T, Torreggiani WC. Recurrent pyogenic cholangitis due to chronic infestation with Clonorchis sinensis (2006: 8b). Eur Radiol 2006;16: 2612-2614.

69. Oh JT, Kang DB, Jo HJ. Acute cholecystitis associated with Clonorchis sinensis infection. Ann Surg Treat Res 2014;87:104-107.

70. Lai CH, Chin C, Chung HC, et al. Clonorchiasisassociated perforated eosinophilic cholecystitis. Am J Trop Med Hyg 2007;76:396-398.

71. Rohela M, Johari S, Jamaiah I, et al. Acute cholecystitis caused by Clonorchis sinensis. Southeast Asian J Trop Med Public Health 2006;37:648-651.

72. Choi JH, Kim JH, Kim CH, et al. Pancreatic mucinous cystadenoma of borderline malignancy associated with Clonorchis sinensis. Korean J Intern Med 2015;30:398401.

73. Centers for Disease Control and Prevention. Fasciola 2013. Available at: https://www.cdc.gov/parasites/fasciola/ Accessed August 28, 2018.

74. Gulsen MT, Savas MC, Koruk M, et al. Fascioliasis: A report of five cases presenting with common bile duct obstruction. Netherlands J Med 2006;64:17-19.

75. Ashdhir P, Sharma SS, Sharma G. Biliary colic with dilated common bile duct: Simple "sheepish" problem? J Indian Med Assoc 2014;112:122-123.

76. Al Qurashi H, Masoodi I, Al Sofiyani M, et al. Biliary fascioliasis-An uncommon cause of recurrent biliary colics: Report of a case and brief review. German Med Sci e-journal. 2012;10:Doc10.

77. Kim SH, Jung CK, Her J, et al. [A case of fascioliasis in the intrahepatic duct with concurrent clonochiasis] (Kor). Korean J Gastroenterol 2014;64:298-301.

78. Bestas R, Yalcin K, Cicek M. Cholestasis caused by Fasciola gigantica. Turk Parazitol Derg 2014;38:201204.

79. Centers for Disease Control and Prevention. Oesophagostomiasis 2019. Available at: https://www.cdc.gov/ dpdx/oesophagostomiasis/index.htmlq Accessed 26 July 2019.

80. Pit DS, Rijcken FE, Raspoort EC, et al. Geographic distribution and epidemiology of Oesophagostomum bifurcum and hookworm infections in humans in Togo. Am J Trop Med Hyg 1999;61:951-955.

81. Polderman AM, Krepel HP, Baeta S, et al. Oesophagostomiasis, a common infection of man in northern Togo and Ghana. Am J Trop Med Hyg 1991;44:336-344.

82. Storey PA, Faile G, Hewitt E, et al. Clinical epidemiology and classification of human oesophagostomiasis. Trans R Soc Trop Med Hyg 2000;94:177-182.

83. Ziem JB, Spannbrucker N, Magnussen P, et al. Oesophagostomum bifurcum-induced nodular pathology in a highly endemic area of northern Ghana. Trans R Soc Trop Med Hyg 2005;99:417-422.

84. Ziem JB, Spannbrucker N, Olsen A, et al. Mass treatment with albendazole reduces the prevalence and severity of 
Oesophagostomum-induced nodular pathology in northern Ghana. Trans R Soc Trop Med Hyg 2006;100:760-766.

85. Taylor GH. Cytomegalovirus. Am Fam Physician 2003; 67:519-524.

86. Zuhair M, Smit GSA, Wallis G, et al. Estimation of the worldwide seroprevalence of cytomegalovirus: A systematic review and meta-analysis. Rev Med Virol 2019; 29:e2034.

87. Gronborg HL, Jespersen S, Honge BL, et al. Review of cytomegalovirus coinfection in HIV-infected individuals in Africa. Rev Med Virol 2017;27.

88. Adland E, Klenerman P, Goulder P, Matthews PC. Ongoing burden of disease and mortality from HIV/CMV coinfection in Africa in the antiretroviral therapy era. Front Microbiol 2015;6:1016.

89. Bates M, Brantsaeter AB. Human cytomegalovirus (CMV) in Africa: A neglected but important pathogen. J Virus Erad 2016;2:136-142.

90. Painter NS, Burkitt DP. Diverticular disease of the colon: A deficiency disease of Western civilization. Br Med J 1971;2:450-454.

91. Madiba TE, Mokoena T. Pattern of diverticular disease among Africans. East Afr Med J 1994;71:644-646.

92. Ihekwaba FN. Diverticular disease of the colon in black Africa. J R Coll Surg Edinburgh 1992;37:107109.

93. Walker AR, Segal I. Epidemiology of noninfective intestinal diseases in various ethnic groups in South Africa. Israel J Med Sci 1979;15:309-313.

94. Patton GC, Coffey C, Sawyer SM, et al. Global patterns of mortality in young people: A systematic analysis of population health data. Lancet 2009;374:881-892.

95. Kotagal M, Agarwal-Harding KJ, Mock C, et al. Health and economic benefits of improved injury prevention and trauma care worldwide. PloS One 2014;9:e91862.

96. McQuillan TJ, Cai LZ, Corcoran-Schwartz I, et al. Surgical site infections after open reduction internal fixation for trauma in low and middle human development index countries: A systematic review. Surg Infect 2018;19:254263.

97. Stanley CM, Rutherford GW, Morshed S, et al. Estimating the healthcare burden of osteomyelitis in Uganda. Trans R Soc Trop Med Hyg 2010;104:139-142.

98. Johnston LE, Stewart BT, Yangni-Angate H, et al. Peripheral arterial disease in sub-Saharan Africa: A review. JAMA Surg 2016;151:564-572.

99. Hu FB. Globalization of diabetes: The role of diet, lifestyle, and genes. Diabetes Care 2011;34:1249-1257.

100. Mpirimbanyi C, Rickard J, Furaha C, Ntirenganya F. Necrotizing soft tissue infections at a tertiary referral hospital in Rwanda: Epidemiology and risk factors for mortality. World J Surg 2018;42:2314-2320.

101. Eke N. Fournier's gangrene: A review of 1726 cases. Br J Surg 2000;87:718-728.

102. Abrahamian FM, Goldstein EJ. Microbiology of animal bite wound infections. Clin Microbiol Rev 2011;24:231246.

103. Animal Bites. Fact Sheets [2018]. Available at: https:// www.who.int/news-room/fact-sheets/detail/animal-bites Accessed 1 February 2019.

104. Ellis R, Ellis C. Dog and cat bites. Am Fam Physician 2014;90:239-243.

105. Centers for Disease Control and Prevention. B virus (herpes B, monkey B virus, herpesvirus simiae, and her- pesvirus B) 2019. Available at: https://www.cdc.gov/ herpesbvirus/index.html Accessed 1 February 2019.

106. Wagener M, Naidoo M, Aldous C. Wound infection secondary to snakebite. S Afr Med J 2017;107:315-319.

107. Chen CM, Wu KG, Chen CJ, Wang CM. Bacterial infection in association with snakebite: A 10-year experience in a northern Taiwan medical center. J Microbiol Immunol Infect 2011;44:456-460.

108. Centers for Disease Control and Prevention. Lymphatic filariasis: Epidemiology and risk factors 2018. Available at: https://www.cdc.gov/parasites/lymphaticfilariasis/ epi.html Accessed 17 September 2018.

109. Lim KH, Speare R, Thomas G, Graves P. Surgical treatment of genital manifestations of lymphatic filariasis: A systematic review. World J Surg 2015;39:2885-2899.

110. Michael E, Bundy DA, Grenfell BT. Re-assessing the global prevalence and distribution of lymphatic filariasis. Parasitology 1996;112:409-428.

111. Centers for Disease Control and Prevention. Parasites: Lymphatic filariasis 2018. Available at: https://www.cdc .gov/parasites/lymphaticfilariasis/treatment.html Accessed 1 February 2019.

112. Cormier JN, Rourke L, Crosby M, et al. The surgical treatment of lymphedema: A systematic review of the contemporary literature (2004-2010). Ann Surg Oncol 2012;19:642-651.

113. Centers for Disease Control and Prevention. Leishmaniasis: Epidemiology and risk factors 2018. Available at: https://www.cdc.gov/parasites/leishmaniasis/epi.html Accessed September 6, 2018.

114. Frolich S, Kaplan I. Plastic surgery in the treatment of cutaneous leishmaniasis of the face. Plast Reconstr Surg 1967;40:157-160.

115. Azab AS, Kamal MS, el-Haggar MS, et al. Early surgical treatment of cutaneous leishmaniasis. J Dermatol Surg Oncol 1983;9:1007-1012.

116. Marcoval J, Penin RM. Evolution of cutaneous leishmaniasis in the last 30 years in a tertiary hospital of the European Mediterranean coast. Int J Dermatol 2017;56: 750-753.

117. Alon D, Chowers M. Successful therapeutic splenectomy in an HIV patient with relapsing visceral leishmaniasis. Int J STD AIDS 2012;23:289-290.

118. Dutra RA, Dutra LF, Reis Mde O, Lambert RC. Splenectomy in a patient with treatment-resistant visceral leishmaniasis: A case report. Rev Socied Brasil Med Trop 2012;45:130-131.

119. Pickering H, Bethune R, Eyre-Brook IA. Diagnostic splenectomy for visceral leishmaniasis. Ann R Coll Surg Engl 2009;91:W1-W2.

120. Troya J, Casquero A, Muniz G, et al. The role of splenectomy in HIV-infected patients with relapsing visceral leishmaniasis. Parasitology 2007;134:621-624.

121. Rees PH, Kager PA, Kyambi JM, et al. Splenectomy in kala-azar. Trop Geograph Med 1984;36:285-292.

122. Lyngdoh E, Jain SC, Barua P. Splenectomy in treatment of drug resistant kala-azar. J Indian Med Assoc 1971;57: 458-461.

123. Kelemen E, Csati M. [Case of kala-azar in an adult in Szeged: Recovery following splenectomy]. Magyar Belorv Arch 1955;8:129-131.

124. Enwonwu CO. Noma: A neglected scourge of children in sub-Saharan Africa. Bull World Health Organ 1995;73: 541-545. 
125. Enwonwu CO, Falkler WA Jr, Phillips RS. Noma (cancrum oris). Lancet 2006;368:147-156.

126. Adolph HP, Yugueros P, Woods JE. Noma: A review. Ann Plast Surg 1996;37:657-668.

127. Baratti-Mayer D, Pittet B, Montandon D, et al. Noma: An "infectious" disease of unknown aetiology. Lancet Infect Dis 2003;3:419-431.

128. Bourgeois DM, Diallo B, Frieh C, Leclercq MH. Epidemiology of the incidence of oro-facial noma: A study of cases in Dakar, Senegal, 1981-1993. Am J Trop Med Hyg 1999;61:909-913.

129. Koigi-Kamau R, Kabare LW, Wanyoike-Gichuhi J. Incidence of wound infection after caesarean delivery in a district hospital in central Kenya. E Afr Med J 2005;82: 357-361.

130. Allegranzi B, Bagheri Nejad S, Combescure C, et al. Burden of endemic health-care-associated infection in developing countries: Systematic review and metaanalysis. Lancet 2011;377:228-241.

131. Global Surgical Collaborative. Surgical site infection after gastrointestinal surgery in high-income, middle-income, and low-income countries: A prospective, international, multicentre cohort study. Lancet Infect Dis 2018;18:516525.

132. Biccard BM, Madiba TE, Kluyts HL, et al. Perioperative patient outcomes in the African Surgical Outcomes study: A 7-day prospective observational cohort study. Lancet 2018;391:1589-1598.

133. Boerma T, Ronsmans C, Melesse DY, et al. Global epidemiology of use of and disparities in caesarean sections. Lancet 2018;392:1341-1348.

134. Harrison MS, Goldenberg RL. Cesarean section in subSaharan Africa. Matern Health Neonatol Perinatol 2016;2: 6.

135. Brubaker SG, Friedman AM, Cleary KL, et al. Patterns of use and predictors of receipt of antibiotics in women undergoing cesarean delivery. Obstet Gynecol 2014;124: 338-344.

136. Sobhy S, Arroyo-Manzano D, Murugesu N, et al. Maternal and perinatal mortality and complications associated with caesarean section in low-income and middleincome countries: A systematic review and meta-analysis. Lancet 2019;393:1973-1982.

137. Hickson E, Harris J, Brett D. A journey to zero: Reduction of post-operative cesarean surgical site infections over a five-year period. Surg Infect 2015;16:174-177.

138. Mpogoro FJ, Mshana SE, Mirambo MM, et al. Incidence and predictors of surgical site infections following caesarean sections at Bugando Medical Centre, Mwanza, Tanzania. Antimicrob Resist Infect Control 2014;3:25.

139. Zuarez-Easton S, Zafran N, Garmi G, Salim R. Postcesarean wound infection: Prevalence, impact, prevention, and management challenges. Int J Womens Health 2017; 9:81-88.

140. Chu K, Cortier H, Maldonado F, et al. Cesarean section rates and indications in sub-Saharan Africa: A multicountry study from Medecins sans Frontieres. PloS One 2012;7:e44484.

141. Young S, Lie SA, Hallan G, et al. Low infection rates after 34,361 intramedullary nail operations in 55 low- and middle-income countries: Validation of the Surgical Implant Generation Network (SIGN) online surgical database. Acta Orthopaed 2011;82:737-743.
142. Cai LZ, Foster D, Kethman WC, et al. Surgical site infections after inguinal hernia repairs performed in Low and Middle Human Development Index countries: A systematic review. Surg Infect 2018;19:11-20.

143. Forrester JD, Cai LZ, Zeigler S, Weiser TG. Surgical site infection after sternotomy in Low- and Middle-Human Development Index countries: A systematic review. Surg Infect 2017;18:774-779.

144. Lessa FC, Winston LG, McDonald LC. Burden of Clostridium difficile infection in the United States. N Engl J Med 2015;372:2369-2370.

145. McDonald LC, Gerding DN, Johnson S, et al. Clinical Practice Guidelines for Clostridium difficile Infection in Adults and Children: 2017 Update by the Infectious Diseases Society of America (IDSA) and Society for Healthcare Epidemiology of America (SHEA). Clin Infect Dis 2018;66:987-994.

146. Forrester JD, Cai LZ, Mbanje C, et al. Clostridium difficile infection in Low- and Middle-Human Development Index countries: A systematic review. Trop Med Int Health 2017;22:1223-1232.

147. Roldan GA, Cui AX, Pollock NR. Assessing the burden of Clostridium difficile infection in low- and middle-income countries. J Clin Microbiol 2018;56.

148. Centers for Disease Control and Prevention. Tuberculosis: Data and Statistics 2018. Available at: https://www.cdc .gov/tb/statistics/default.htm Accessed September 24, 2018.

149. World Health Organization. Global Tuberculosis Report. Geneva: World Health Organization, 2018.

150. World Health Organization. Global Tuberculosis Report 2017. Available at: www.who.int/tb/publications/global_ report/gtbr2017_main_text.pdf Accessed 24 September 2018.

151. Falzon D, Schunemann HJ, Harausz E, et al. World Health Organization treatment guidelines for drug-resistant tuberculosis, 2016 update. Eur Respir J 2017;49.

152. Takeda S, Maeda H, Hayakawa M, et al. Current surgical intervention for pulmonary tuberculosis. Ann Thorac Surg 2005;79:959-963.

153. Fry DE. Extra-pulmonary tuberculosis and its surgical treatment. Surg Infect 2016;17:394-401.

154. Somocurcio JG, Sotomayor A, Shin S, et al. Surgery for patients with drug-resistant tuberculosis: Report of 121 cases receiving community-based treatment in Lima, Peru. Thorax 2007;62:416-421.

155. World Health Organization. The role of surgery in the treatment of pulmonary TB and multidrug- and extensively drug-resistant TB 2014. Available at: www.euro.who .int/_data/assets/pdf_file/0005/259691/The-role-of-surgeryin-the-treatment-of-pulmonary-TB-and-multidrug-andextensively-drug-resistant-TB.pdf Accessed September 24, 2018.

156. LRI Collaborators. Estimates of the global, regional, and national morbidity, mortality, and aetiologies of lower respiratory tract infections in 195 countries: A systematic analysis for the Global Burden of Disease Study 2015. Lancet Infect Dis 2017;17:1133-1161.

157. Rudan I, El Arifeen S, Bhutta ZA, et al. Setting research priorities to reduce global mortality from childhood pneumonia by 2015. PLoS Med 2011;8:e1001099.

158. Sahn SA. Diagnosis and management of parapneumonic effusions and empyema. Clin Infect Dis 2007;45:14801486. 
159. World Health Organization. Chagas disease (American trypanosomiasis) 2019. Available at: https://www.who .int/chagas/epidemiology/en/ Accessed 1 February 2019.

160. World Heatlh Organization. Chagas disease (American trypanosomiasis) Fact Sheets 2019. Available at: https:// www.who.int/en/news-room/fact-sheets/detail/chagasdisease-(american-trypanosomiasis Accessed 1 February 2019.

161. Magarakis M, Macias AE, Tompkins BA, et al. Cardiac surgery for Chagas disease. J Card Surg 2018;33:597-602.

162. de Oliveira RB, Troncon LE, Dantas RO, Menghelli UG. Gastrointestinal manifestations of Chagas' disease. Am J Gastroenterol 1998;93:884-889.

163. Wyber R, Zuhlke L, Carapetis J. The case for global investment in rheumatic heart-disease control. Bull World Health Organ 2014;92:768-770.

164. Woldu B, Bloomfield GS. Rheumatic heart disease in the Twenty-First Century. Curr Cardiol Rep 2016;18:96.

165. Watkins DA, Johnson CO, Colquhoun SM, et al. Global, regional, and national burden of rheumatic heart disease, 1990-2015. N Engl J Med 2017;377:713-722.

166. Alkire BC, Raykar NP, Shrime MG, et al. Global access to surgical care: A modelling study. Lancet Glob Health 2015;3:e316-e323.

167. Weiser TG, Haynes AB, Molina G, et al. Size and distribution of the global volume of surgery in 2012. Bull World Health Organ 2016;94:201-209F.

168. Hoyler M, Finlayson SR, McClain CD, et al. Shortage of doctors, shortage of data: A review of the global surgery, obstetrics, and anesthesia workforce literature. World J Surg 2014;38:269-280.

169. Holmer H, Lantz A, Kunjumen T, et al. Global distribution of surgeons, anaesthesiologists, and obstetricians. Lancet Glob Health 2015;3(Suppl 2):S9-S11.

170. deVries CR, Rosenberg JS. Global surgical ecosystems: A need for systems strengthening. Ann Glob Health 2016; 82:605-613.

171. Allegranzi B, Zayed B, Bischoff P, et al. New WHO recommendations on intraoperative and postoperative measures for surgical site infection prevention: An evidence-based global perspective. Lancet Infect Dis 2016;16:e288-e303.

172. Pantosti A, Del Grosso M. Giornata europea degli antibiotici: uso responsabile per il controllo dell'antibioticoresistenza [European Antibiotics Day: Responsible use for the antibiotic-resistance control] 2009. Available at: http:// old.iss.it/binary/publ/cont/0932web.pdf Accessed 6 July 2018.

173. Schuts EC, Hulscher M, Mouton JW, et al. Current evidence on hospital antimicrobial stewardship objectives: A systematic review and meta-analysis. Lancet Infect Dis 2016;16:847-856.

174. Sipahi OR. Economics of antibiotic resistance. Expert Rev Anti Infect Ther 2008;6:523-539.

175. Cox JA, Vlieghe E, Mendelson M, et al. Antibiotic stewardship in low- and middle-income countries: The same but different? Clin Microbiol Infect 2017;23:812-818.

176. World Health Organization Rational Use of Medicines: The World Medicines Situation 2011. Geneva: World Health Organization, 2011.

177. Cuong NV, Padungtod P, Thwaites G, Carrique-Mas JJ. Antimicrobial usage in animal production: A review of the literature with a focus on low- and middle-income countries. Antibiotics 2018;7:pii E75.
178. European Centre for Disease Prevention and Control. Summary of the latest data on antibiotic consumption in the European Union, November 2016. Available at: www.ecdc .europa.eu/sites/portal/files/documents/antibiotics-ESACNet\%20Summary\%202016_0.pdf Accessed 6 July 2018.

179. Antimicrobial resistance: Global Report on Surveillance. Genever: World Health Organization, 2017.

180. World Health Organization. Prioritization of pathogens to guide discovery, research, and development of new antibiotics for drug-resistant bacterial infections, including tuberculosis. Geneva: World Health Organization, 2017.

181. World Health Organization. Antimicrobial Resistance: Global Report on Surveillance. Geneva: World Health Organization, 2014.

182. O'Neill J. Review on Antimicrobial Resistance. Antimicrobial resistance: Tackling a crisis for the health and wealth of nations. 2014. https://amr-review.org/sites/ default/files/AMR\%20Review\%20Paper\%20\%20Tackling $\% 20$ a\%20crisis $\% 20$ for $\% 20$ the $\% 20$ health $\% 20$ and $\% 20$ wealth $\% 20$ of\%20nations_1.pdf (last accessed October 17, 2019).

183. Zaidi AK, Huskins WC, Thaver D, et al. Hospital-acquired neonatal infections in developing countries. Lancet 2005; 365:1175-1188.

184. Okeke IN, Laxminarayan R, Bhutta ZA, et al. Antimicrobial resistance in developing countries $\mathrm{I}$ : Recent trends and current status. Lancet Infect Dis 2005;5:481493.

185. World Health Organization. Global Priority List of Antibiotic-Resistance Bacteria to Guide Research, Discovery, and Development of New Antibiotics. Geneva: World Health Organization, 2017.

186. Laxminarayan R, Duse A, Wattal C, et al. Antibiotic resistance: The need for global solutions. Lancet Infect Dis 2013;13:1057-1098.

187. Ashley EA, Recht J, Chua A, et al. An inventory of supranational antimicrobial resistance surveillance networks involving low- and middle-income countries since 2000. J Antimicrob Chemother 2018;73:1737-1749.

188. Ashley EA, Recht J, Chua A. et al. Antimicrobial resistance in low and middle income countries. An analysis of surveillance networks. Report 2017. https://www.iddo .org/amr/about-us/amr-networks (last accessed October 17, 2019).

189. Davey P, Brown E, Charani E, et al. Interventions to improve antibiotic prescribing practices for hospital inpatients. Cochrane Database System Rev 2013:CD003543.

190. Bhalla N, Hussein N, Atari M, et al. Introducing an antibiotic stewardship program in a humanitarian surgical hospital. Am J Infect Control 2016;44:1381-1384.

191. Sarwar MR, Saqib A, Iftikhar S, Sadiq T. Knowledge of community pharmacists about antibiotics, and their perceptions and practices regarding antimicrobial stewardship: A cross-sectional study in Punjab, Pakistan. Infect Drug Resist 2018;11:133-145.

192. Donabedian A. The quality of care: How can it be assessed? JAMA 1988;260:1743-1748.

193. World Health Organization. Improving infection prevention and control at the health facility: Interim practical manual supporting implementation of the WHO Guidelines on Core Components of Infection Prevention and Control Programmes. Geneva: World Health Organization; 2018.

194. Rhodes A, Evans LE, Alhazzani W, et al. Surviving Sepsis Campaign: International guidelines for management of 
sepsis and septic shock: 2016. Crit Care Med 2017;45: 486-552.

195. Sawyer RG, Claridge JA, Nathens AB, et al. Trial of short-course antimicrobial therapy for intraabdominal infection. N Engl J Med 2015;372:1996-2005.

196. World Health Organization. Global Guidelines for the Prevention of Surgical Site Infection. Geneva: World Health Organization, 2016.

197. WHO Guidelines for Safe Surgery. Geneva: World Health Organization, 2009.

198. Allegranzi B, Bischoff $\mathrm{P}$, de Jonge $\mathrm{S}$, et al. New WHO recommendations on preoperative measures for surgical site infection prevention: An evidence-based global perspective. Lancet Infect Dis 2016;16:e276-e287.

199. Berrios-Torres SI, Umscheid CA, Bratzler DW, et al. Centers for Disease Control and Prevention Guideline for the Prevention of Surgical Site Infection, 2017. JAMA Surg 2017;152:784-791.

200. Consensus paper on the surveillance of surgical wound infections. The Society for Hospital Epidemiology of America; The Association for Practitioners in Infection Control; The Centers for Disease Control; The Surgical Infection Society. Infect Control Hosp Epidemiol 1992; 13:599-605.

201. GlobalSurg Collaborative. 2018. Available at: www.global surg.or. Accessed 1 May 2018.

202. World Health Organization. Primary Surgical Care Package. Geneva: World Health Organization.

203. Tartari E, Weterings V, Gastmeier P, et al. Patient engagement with surgical site infection prevention: An expert panel perspective. Antimicrob Resist Infect Control 2017;6:45.

204. McIntosh S, Perez-Ramos J, Demment MM, et al. Development and implementation of culturally tailored offline mobile health surveys. JMIR Public Health Surveill 2016;2:e28.

205. Kasatpibal N, Norgaard M, Jamulitrat S. Improving surveillance system and surgical site infection rates through a network: A pilot study from Thailand. Clin Epidemiol 2009;1:67-74.
206. Matousek A, Paik K, Winkler E, et al. Community health workers and smartphones for the detection of surgical site infections in rural Haiti: A pilot study. Lancet 2015; 385(Suppl 2):S47.

207. Berrevoets MA, Ten Oever J, Sprong T, et al. Monitoring, documenting and reporting the quality of antibiotic use in the Netherlands: A pilot study to establish a national antimicrobial stewardship registry. BMC Infect Dis 2017;17:565.

208. Barlam TF, Cosgrove SE, Abbo LM, et al. Implementing an antibiotic stewardship program: Guidelines by the Infectious Diseases Society of America and the Society for Healthcare Epidemiology of America. Clin Infect Dis 2016;62:e51-e77.

209. Abbo LM, Cosgrove SE, Pottinger PS, et al. Medical students' perceptions and knowledge about antimicrobial stewardship: How are we educating our future prescribers? Clin Infect Dis 2013;57:631-638.

210. Mwai GW, Mburu G, Torpey K, et al. Role and outcomes of community health workers in HIV care in sub-Saharan Africa: A systematic review. J Int AIDS Soc 2013;16: 18586.

211. Koon AD, Goudge J, Norris SA. A review of generalist and specialist community health workers for delivering adolescent health services in sub-Saharan Africa. Hum Resour Health 2013;11:54.

212. Newman PM, Franke MF, Arrieta J, et al. Community health workers improve disease control and medication adherence among patients with diabetes and/or hypertension in Chiapas, Mexico: An observational stepped-wedge study. BMJ Glob Health 2018;3:e000566.

Address correspondence to:

Dr. Jennifer Rickard Department of Surgery University of Minnesota 420 Delaware Street SE, MMC 195 Minneapolis, MN 55455 USA

E-mail: gehr0059@umn.edu 